\title{
JOHN RAWLS VERSUS JOHN POCOCK: JUSTICIA FRENTE A "BUEN GOBIERNO»1
}

\author{
ELOY GARCÍA \\ Catedrático de Derecho Constitucional \\ Universidad de Vigo
}
SUMARIO
I. Introducción "civis romanus sum". Poder o ciudadanía: la crisis de las ideologías y el retorno de la Política
II. La postmodernidad como «segundo asalto a la razón". La postmodernidad y sus diferentes alternativas críticas: Derecho frente a Política. La política como "Buen gobierno".
III. El "Momento maquiavélico" de John Pocock: La contextualización del discurso político en el tiempo. El paradigma republicano cívico.

\section{INTRODUCCIÓN: "CIVIS ROMANUS SUM". PODER O CIUDADANÍA: LA CRISIS DE LAS IDEOLOGÍAS Y EL RETORNO DE LA POLÍTICA}

Hace casi dos mil años en Jerusalén, un hombre llamado Pablo de Tarso que había sido arrestado por escandalizar al pueblo, fue atado con correas para ser flagelado y torturado a fin de que confesara su delito. Pablo que en

1. Este texto reélabora y profundiza las ideas en relación al conflicto entre la concepción formalista y jurisdicista del dérecho y la constitución, y la concepción de la política como "buen gobierno" que se recogen en el estudio que precederá a la traducción española del libro $E l$ Momento Maquiavélico de John Pocock, de inmediata publicación en la editorial Tecnos, Madrid 2002; algunas de las cuales ya fueron anticipadas en el libro El Estado Constitucional ante su Momento maquiavélico, Civitas, Madrid 2000. 
el camino a Damasco había dejado, junto a su nombre judío de Saulo, la religión de sus mayores para abrazar una fe que hacía de la humildad la primera de las virtudes, no dudó en espetar con orgullo al procurador de Roma: "civis romanus sun" -soy ciudadano romano- ${ }^{2}$. Y es que a pesar de ser cristiano, a pesar de profesar una fe que veía en la tortura y en la muerte en la cruz, un signo de redención de la humanidad, Pablo de Tarso -nuestro san Pablo- no quiso, o no pudo, renunciar al orgullo de proclamarse ciudadano de Roma y a lo que ello significaba.

Ser ciudadano romano comportaba -incluso en la tardía época de los primeros años de Cristo cuando los Césares habían despojado al Senatus et Populusque Romanus de sus viejas atribuciones de imperio- una prolija relación de derechos y deberes políticos, fiscales y militares, como el de no ser sometido a tortura, el de participar en los comicios, el de recorrer el cursus bonorum que conducía a las más importantes magistraturas y al Senado. Ser ciudadano romano implicaba, ante todo, formar parte de una comunidad política -la civitas- en la que el hombre ejercía en primera persona los derechos inherentes a eso que hoy llamamos soberanía ${ }^{3}$.

Veinte siglos más tarde en Berlín, ante el muro que dividía el muro en dos, un presidente de los Estados Unidos, John Fitzgerald Kennedy, acudía a las palabras de Pablo de Tarso para expresar el orgullo de pertenecer al mundo libre, de ser ciudadano de una Democracia Constitucional:

"Hace dos mil años el mayor orgullo para un hombre era decir: civis romanus sum. Hoy en el mundo de la libertad el mayor orgullo de un hombre es poder decir: Ich bin ein berliner (Yo también soy berlinés). Hay mucha gente en el mundo que no comprende -o que dice no comprender- cuál es el gran problema que divide al mundo libre del mundo comunista. iQue vengan a Berlín! Hay algunos que dicen que el comunismo representa el camino al futuro. ¿Que vengan a Berlín! ¿Que vengan a Berlín! Y hay otros pocos, en Europa y en otras partes, que dicen que es verdad que el comunismo resulta un sistema malvado, pero que permite realizar el progreso económico. ¡Lass sie nach Berlin kommen! (jDejadles venir a Berlin!): la libertad tiene muchas dificultades y la democracia no es perfecta, pero nosotros no hemos tenido que erigir un muro para encerrar dentro a nuestra gente e impedirla marcharse... Cuando todos seamos libres podremos mirar el día en que esta ciudad resulte reunificada -y con ella, todo el país y todo el continente Europeo- en un mundo pacífico y rico en esperanza. Cuando ese día llegue -y llegará- la población de Berlín podrá tener un motivo de satisfacción en el hecho de haber estado en primera línea del frente durante varias décadas."

2. Hechos de los Apóstoles 22, 22-29.

3. John Pocock en un reciente estudio ha puesto de manifiesto el proceso de descomposición de la noción de ciudadanía romana en el Imperio proyectando sus consecuencias en la época contemporánea. Véase "The ideal of Citizenship Since Classical Times" en Ronald Beiner (edit.), Theorizing Citizenship, Nueva York, 1995. 
Treinta y cinco años después el muro que separaba al mundo libre del mundo comunista se derrumbaba como un azucarillo para permitir la extensión a todos los confines de la tierra de los postulados del constitucionalismo: de las ideas de Constitución, derechos del hombre, legalidad y juridicidad del poder, representación, partidos y elecciones libre. El día anunciado por el presidente Kennedy había llegado ya, y, sin embargo, la recién adquirida libertad y la condición de ciudadano libre, no parecía traer a los hombres la paz con justicia y el orgullo prometidos. Incluso en la patria de la libertad, en las Democracias Constitucionales, comenzaba a evidenciarse una creciente degradación en los valores, en las normas, en las instituciones, de lo político y de lo jurídico, una degradación que carecía de cobertura, que no encontraba justificación, en la dialéctica de contrarios que hasta hacía poco había dividido el mundo en dos.

$Y$ es que contrariamente a lo que apuntaban las apariencias, las piedras que a su caída desprendíía el muro de Berlín habían golpeado en los dos lados del "telón de acero" y no sólo en uno. Era la corroboración del acierto de la tesis que durante años fuera hipótesis de trabajo de Henry Lefevbre: desde el triunfo de Stalin en la Unión Soviética, mundo capitalista y mundo socialista constituían el adverso y el reverso de una sola moneda, de un sólo discurso histórico perfectamente trabado en torno a un hilo conductor común. La crisis del Estado socialista se revelaba así también, la crisis de su rival el Estado Constitucional Democrático. Una crisis que como recordara con una agudeza no exenta de gracejo Idro Montanelli - Votaré a la democracia cristiana aunque tenga que taparme la nariz para no oler los hedores que despide la urna porque quiero evitar el triunfo del comunismon- durante todo aquel tiempo a duras penas se había mantenido oculta tras el ejemplo negativo que representaba el bloque del Este.

En ese sentido, resulta evidente que en los últimos años los signos de crisis en el mundo constitucional no han hecho sino multiplicarse. La pérdida de referentes y de significación en los discursos que lleva al debate público a la vacuidadd $^{4}$, la confiscación del aparato institucional del Estado y de su potestad por una clase política que opera siguiendo una lógica ajena a la idea democrática $^{5}$, el rotundo fracaso de la representación política y la probada ine-

4. En un mundo en que no se confrontan ideologías el debate político se ha visto sustituido por el debate sobre trivialidades que hábilmente dirigido por expertos en comunicación, solemniza lo obvio, eléva a la categoría de fundamental lo banal y hace de la politica un gigantesco mercado en el que se lucha por un poder que ha perdido toda coloración. Es el reino del marketing, donde la imagen se hace sustancia, en el que lo conveniente es no decir nada que signifique compromiso irrenunciable, y donde un agujero en un zapato puede dar lugar a la pérdida de las elecciones.

5. La profesionalización de la política ha provocado la aparición de una clase política cuya sola existencia ataca la esencia misma de la democracia, causa su degeneración y se convierte en el mayor enemigo de los principios que en buena lógica debieran inspirar al Estado Constitucional Democrático. El libro de Klaus von Beyme, La clase política en el Estado de Partidos, Madrid, 
ficacia de los mecanismos de responsabilidad ${ }^{6}$, la progresiva esclerosis de toda una serie de instrumentos de sociabilidad política como partidos y sindicatos ${ }^{7}$, $y$, en general, el debilitamiento e incluso la parálisis de la iniciativa social en una forma política que paradójicamente se define como Goverment by society (Estado de la sociedad) ${ }^{8}$, la paulatina transformación de la judicatura en un poder y la creciente preponderancia de unos grupos (poderes en expresión de Giorgio Lombardi) privados que hacen inoperantes tanto los tradicionales sistemas de protección jurisdiccional como el ordenamiento jurídico ${ }^{9}$, la evi-

1995, además de un estudio empírico sobre el tema, constituye un reconocimiento expreso por la Ciencia Política democrática del hecho mismo de la existencia de "una clase política" nacida de y por los partidos.

6. El viejo aforismo crítico de Rousseau contra la representación («Le peuple anglais pense étre libre; il se trompe fort, il ne l'est que durant l'élection des membres du parlement; si tôt qu'ils sont élus, il est esclave, il n'est rien. Dans les courts moments de sa liberté l'usage qu'il en fait mérite bien qu'il la perde". Contrato Social, libro III, capítulo XV), hoy resulta insuficiente para describir la realidad de lo que está sucediendo porque el control mediático de la sociedad hace difícil que los electores sean libres, incluso en el momento de depositar su voto en las urnas. Obviamente la crítica tiene límites: no es lo mismo la crisis de la representación en países en que históricamente ha venido funcionado con dificultad -Italia, Portugal o España- que la crisis allí dónde existe una vieja tradición arraigada y socialmente respetada -caso de Gran Bretaña, donde los soldados que carecían de ropa de abrigo en el frente de Montecasino durante la Segunda Guerra Mundial, no protestaban a sus oficiales porque sabían que no podían hacer nada al respecto, sino que se dirigían por carta a sus respectivos diputados quienes, a su vez, interpelaban duramente al gobierno en los Comunes-.

Naturalmente alli donde no funciona la representación tampoco puede hacerlo la responsabilidad. Expresiones como "Vous avec juridiquement tort parce que vous êtes politiquement minoritaire" (palabras pronunciadas por el diputado socialista André Laignel en la tribuna de la Asamblea Nacional en 1981) o la fórmula "Responsable, mais pas coupable" acuñada en Francia a raíz del affaire que envolvió al gobierno Fabius en relación con las transfusiones de sangre contaminada por el sida, son en sí mismas todo un símbolo de la situación a la que ha llegado la degradación de la responsabilidad política de los gobernantes en el Estado Constitucional Democrático.

7. En los partidos "atrápalo todo" -el cacht all party de. Kircheimer- lo único que cuenta es el líder carismático y comunicativo, y el menaje mediático a lanzar a la opinión, el resto, ideología, militancia, estructura tiene poco interés, salvo cuando se pierde el poder y se trata primero de recomponer el liderazgo político interno, y después, de desalojar al rival político del gobierno. En este contexto es en el que una nueva ley de Gresham -la ley de Gresham de la oligarquía partidista- parece haberse abierto camino: sólo que en este caso es el militante burdo y disciplinado $-\mathrm{y}$ no la moneda mala- el que expulsa al inteligente y con iniciativas.

8. Estado nacido o surgido de la sociedad sería la traducción correcta de la expresión de Thomas paine "Governments of Society", una expresión tomada de un aforismo del autor ("derribar los "Governments out of Power" para erigir en su lugar los "Governments out of Society" "), que encarna la voluntad y el sentido democrático último que anima al Estado Constitucional representativo y que toma cuerpo en el régimen de la opinión pública.

9. La judicatura fue concebida durante el siglo XIX como un instrumento de garantía: el instrumento de garantía por excelencia de los derechos del sujeto individual. Su misión era aplicar el derecho positivo codificado tanto para reprimir las violaciones del orden colectivo protegido por el código penal, como para solventar los conflictos que contraponían a los particulares entre sí, o a estos con el Estado. En ese sentido, el juez era un órgano de la ley -lo que equivalía a decir del derecho- no sometido a otra autoridad que la de los códigos, y protegido en su imparcialidad e independencia por un sistema de carrera y por el principio de inamovilidad. Tras la Segunda Guerra Mundial las circunstancias cambiaron y surgieron nuevos problemas: el dere- 
dente desvirtuación de unas libertades individuales que están dejando de ser postulados morales destinados a garantizar la autodeterminación humana para convertirse en medios instrumentales del tráfico mercantil ${ }^{10}[\ldots]$ son síntomas ciertos del preocupante décalage entre teoría y praxis que de tiempo atrás viene corroyendo a la Democracia de los Modernos y que hace que la distancia que media entre cómo es realmente el vivere político, y cómo debiera ser, a juzgar por los postulados de principio que inspiran sus valores, reglas e instituciones, empiece a adquirir un calado tal que -como dijera Maquiavelo"aquel que deja lo que hace por lo que debiera hacer, corra a la ruina en vez de beneficiarse".

Para ponderar adecuadamente lo que está sucediendo en el Estado Constitucional conviene tomar como parámetro de referencia lo acaecido recientemente al otro lado del muro, en el modelo de legitimidad rival: la legitimidad socialista que había servido de soporte y de enmascaramiento a los factores de crisis del mundo occidental. A este respecto se ha dicho que la crisis de los Estados socialistas representa un supuesto típico de crisis de un modelo de legitimidad que desaparece víctima de la impostura ${ }^{11}$, y, en cierto modo, otro tanto de lo mismo se está repitiendo en las Democracias y Constitucionales de

cho desbordó los estrictos límites de la legalidad positiva y se abrió el camino a la heterodoxa vía de la interpretación; los jueces individuales desbordados por la desmesurada tarea de impartir justicia en una sociedad de masas, reclamaron independencia frente a un ejecutivo crecientemente impregnado de ideologías en conflicto y exigieron su autogobierno, y la estructura procesal se complicó y adquirió una dificultad técnica que multiplicó hasta lo inverosímil los requisitos formales. La judicatura dejó de ser un instrumento de garantía fundado en el derecho para restablecer las violaciones singulares que de la legalidad efectuaban sujetos públicos o privados y pasó a convertirse en un poder en sí mismo, y como tal, capaz de imponer unas reglas informales a los ciudadanos que le reclamaban justicia. Fue entonces cuando para añadir complicaciones a una situación de por sí complicada, la crisis del poder político dio fundamento a las pretensiones de ciertos sectores de la judicatura de asumir una función de indirizzo político que en democracia representativa sólo puede corresponder al electo. El problema de la judicatura contemporánea que se mueve entre la pretensión de la acción política y la imposibilidad material de satisfacer las necesidades de justicia de los particulares en una sociedad masificada, tecnificada y crecientemente compleja, estriba en la dificultad de dar adecuada respuesta al reclamante individual que con frecuencia contempla desesperanzado en sus litigios cómo unos poderes privados sobrados en medios y en recursos materiales, imponen su voluntad al derecho con el concurso -o en ocasiones por falta de concurso- de la magistratura.

10. Una de las grandes paradojas de la libertad moderna -la que Berlín llama libertad negativa y que se caracteriza por construir un ámbito de libertad sin obstáculos- es que en el mundo contemporáneo termina convertida en un mero instrumento de goce material y no en un fin en sí mismo al servicio de los grandes valores humanos. Si en sus orígenes filosóficos, en la utopía de los Locke y los teóricos del individualismo, el fin de la libertad era dar al hombre la felicidad, poner al ser humano en condiciones de realizarse en la tierra, en el momento actual la libertad está al servicio de un bienestar material que se identifica simplemente con el mercado: se busca ser libre para consumir no para ser hombre. Una crítica inteligente a las tesis de Berlín en las que ve un intento de descontextualizar, separar y fragmentar los fines morales de la noción de libertad en Skinner "The idea of Negative Liberty" en Rorty, Schneewind y Skinner, Philosophy in History, Cambridge 1984.

11. Véase al respecto lo expuesto en el estudio preliminar a la traducción del libro de Ferrero, Poder. Los genios invisibles de la Ciudad, Madrid, 1998. 
este lado del muro, sólo que a diferencia de las naciones del Este, en el mundo constitucional el principio democrático permanece todavía vivo, la sustancia de su fórmula de legitimidad resulta aún suficientemente creíble para los gobernados que continúan creyendo que el gobierno del pueblo por el pueblo y con el pueblo es la mejor o -en el peor de los casos-, la menos mala de todas las formas de gobierno posibles ${ }^{12}$.

No es pues, que el ideario democrático se encuentre teóricamente cuestionado, no se trata de que su principio constitutivo esté siendo negado, no es que -por mucho que subsistan desafíos no despreciables- existan fórmulas alternativas rivales que como los bárbaros los poeta acechen a las puertas dee la Ciudad para destruirla, ocurre más bien que tras la desaparición de las ideologías, en el Estado Constitucional la lógica del poder ha desplazado, e incluso ha llegado a sustituir por completo, a la lógica de la politica: la dialéctica del poder -la política concebida en sentido weberiano de lucha por el liderazgo, la dominación y la consecución y fidelización de un séquito- ha remplazado a la dialéctica de la política, a las ideas entendidas como instrumento de transformación desde la razón y la ilusión utópica, de una realidad construida en la convivencia colectiva ${ }^{13}$. Y es que sin ideología, el Estado Constitucional-representativo fundado en la confrontación política de los partidos, resulta privado de todo su contenido material y reducido a una mera estructura formal e institucional de poder destinada a imponer una voluntad a los gobernados en la que -en palabras de Tucholsky- los hombres y proyectos no se miden, ni son otra cosa que el ruido que sean capaces de provocar ${ }^{13 \text { bis. }}$

El poder se define, dicho sea en pocas palabras, como la capacidad de imponer a un tercero la propia voluntad, bien recurriendo a la fuerza bien a través de otros medios. El poder es, en esencia, dominación y mando, y, como tal, presupone una diferenciación entre quien lo posee y quienes no lo poseen, entre quienes mandan y aquellos que están destinados a la obediencia, entre gobernantes y gobernados. Quien gobierna manda, y el gobernado se encuen-

12. La fórmula acuñada por Liconln en el discurso conmemorativo de la batalla de Gettysburg es predicable y por tanto, sirve igualmente para el vivere civile como para la democracia representativa. La caracterización de la democracia representativa como la menos mala de todas las formas políticas posibles ("la democracia es la peor forma de gobierno posible excluyendo todas las demás", corresponde a Churchill y representa perfectamente el espíritu que durante la "Guerra fría" sirvió para mantener a la Democracia Constitucional al margen de cualquier crítica.

13. En relación con el particular entendimiento de la política por Weber como una realidad conformada en torno al poder y la dominación, puede verse su conocido ensayo, "La Política como vocación" (1919), traducción española de Francisco Rubio Llorente en Escritos Políticos, Madrid, 1967. Se trata de una obra de excepcional importancia sobre todo porque sus tesis y consideraciones influyeron y repercutieron de manera decisiva en el pensamiento de autores posteriores de la talla y transcendencia de un Schumpeter, un Schmitt o un Kelsen.

13bis. Es en este contexto donde en la era de la postmodernidad y de lo mediático, cabe situar al escándalo político como sustitutivo degenerado de la responsabilidad política. Al respecto John B. Thompson, El escándalo político. Poder y visibilidad en la era de los medios de comunicación, Barcelona 2001. 
tra obligado a obedecer. Por contra la política es bastante más que el simple poder, aun cuando también precise del poder para imponer su voluntad. La política es la forma de organizar la convivencia colectiva del hombre en comunidad (sociedad política), y cuando recibe el calificativo de democrática es porque antes ha hecho del hombre un sujeto activo en la vida pública capaz de ejercer por sí mismo su propio autogobierno, su ciudadanía: una vita activa en el vivere civile. Lo que no es obstáculo para que existan otras fórmulas de democracia, para que la democracia conozca también una alternativa perfectamente democrática en la Democracia Constitucional o Democracia representativa, caracterizada por dos notas: la distinción entre representantes y representados, y la imposición de un límite a la acción de ambos en forma de Constitución.

El Poder Constituyente es el instrumento a través del cual la comunidad crea la Constitución, construye su estructura de gobierno; con él el civis, el hombre politicamente activo y dotado por naturaleza del derecho a autogobernarse, ejerce su ciudadanía activa, proyecta su capacidad natural de obrar político, en un momento y a un solo y exclusivo fin: elaborar un texto normativo en el que encierra las claves constitutivas de su futuro vivir colectivo, y cuando lo hace desaparece ${ }^{14}$, renunciando por, y en ese acto, a toda vita política activa. La Constitución obra del Poder Constituyente (del conjunto de los civis), por un lado tiene como misión estipular en clave de derechos fundamentales los deberes a que se ven sometidos los sujetoos públicos, y, de otro sirve para configurar un sistema equilibrado ("balance") de relaciones entre los poderes constituidos, en el que el indirizzo político corresponde siempre de manera necesaria a un pueblo que a través de la mecánica electoral, confiere a sus gobernantes un trust: deposita en ellos una confianza para la gestión de lo público de la que deberán rendir cuentas periódicamente. Ahora bien, semejante indirizzo se ejerce por intermediación de los partidos que son la manifestación organizada del pluralismo ideológico imperante en la sociedad, es decir, reproducen las diferentes cosmovisiones politicas en pugna en la vida social. Cuando ésta falta, cuando las ideas en contraposición y en conflicto, se debilitan primero para desaparecer luego, quiebra la espina dorsal de todo el sistema y toda la mecánica constitucional entra automáticamente en cuestión. El trust, el control del ejecutivo, la responsabilidad, la elaboración de la legalidad y la supervisión de su ejecución, los instrumentos de garantía y de control ${ }^{15}$ [...] devienen fórmulas huecas y quedan sólo unos partidos que ya no son sino organizaciones, estructuras de poder desprovistas de ideología. El poder como lógica de mando, sustituye entonces a la ideología entendida como expresión utópica de una política construida en y desde los

14. Al respecto el trabajo clásico entre la doctrina española es el ensayo de PEDRO DE VEGA, La Reforma Constitucional y la problemática del Poder Constituyente, Madrid, 1985; en la misma línea JAVIER PÉREZ ROYo, La Reforma Constitucional, Madrid, 1987.

15. Un interesante y por muchas razones encomiable estudio de toda la problemática del Poder desde la categoría de control en el libro de DiEgo VALADÉs, El control del Poder, México, 2000. 
partidos, y el Estado Constitucional evidencia de ese modo su apabullante crisis, una crisis que despeja el camino a lo que Esprit calificó en su día de "retour du politique" ${ }^{15 \mathrm{bis}}$.

\section{LA POSTMODERNIDAD COMO «SEGUNDO ASALTO A LA RAZÓN". LA POSTMODERNIDAD Y SUS DIFERENTES ALTERNATIVAS CRÍTICAS: DERECHO FRENTE A POLÍTICA; «EL BUEN GOBIERNO" ${ }^{16}$}

El pensamiento europeo de los setenta -momento en que aparecen la Téría de la Justicia de John Rawls y el Momento maquiavélico de John Pocock ${ }^{17}$ - se debatía en un marasmo de confusión y desorientación sólo parangonable al estado de desánimo colectivo en que por aquellas fechas se veía sumida una sociedad norteamericana que además de salir derrotada por primera vez en su historia de una guerra, se encontraba profundamente lastimada en su ethos moral por el proceso político-judicial que había llevado a un presidente a renunciar a su cargo ${ }^{17 b i s}$. Mientras América encaraba sus fantasmas, la intelectualidad de izquierda que en los años de la guerra fría había ostentado la indiscutible hegemonía cultural en el con-

15bis. Retour du politique, fue el título del número de julio-agosto de 1976 de la revista Esprit que de algún modo define y anticipa el cambio y la nueva posición que iba a adoptar un grupo de autores franceses Furet, Lastoriadis, Lefort que iniciaban la senda de la recuperación de la política clásica, la política entendida como una realidad autónoma definida por sus propios parámetros. Una línea de pensamiento que siempre se mantuvo viva en el mundo anglosajón en las obras de autores tan importantes como Besmard Crick o Hannah Arendt.

Es importante recordar que poco después del inicio de esta polémica vuelta a la Política el Derecho Político español renunciaba a la política, una renuncia que parece necesario debatir y resplantearse hoy.

16. La terminología ahora utilizada es más coherente con la que los diferentes grupos de autores reconocen como propia que la que se recoge en el título que encabeza el trabajo: para Rawls el objetivo de la comunidad política consiste en alcanzar una vida justa -la Justicia- en las reglas del derecho (Kant) con lo cual lo fundamental es el Derecho, mientras que para Pocock, Skinner y demás miembros de la "escuela de Cambridge" lo fundamental en un mundo en cambio cuyas transformaciones estructurales (mundialización) están poniendo en jaque la estabilidad (gobernabilidad) de los regímenes políticos y la propia existencia de la ciudad, estriba en afirmar la identidad política del hombre como ciudadano -la Política- (Aristóteles), de manera que no les repugna hablar de Justicia en el sentido en que lo hacía Ambrogio Lorenzetti cuando pintaba los frescos del Buen Gobierno en el palacio comunal de Siena.

17. La Teoría de la Justicia se publicó en 1971, mientras el Momento maquiavélico lo fue en 1975 aunque se terminara de redactar dos años antes. En principio pues, las dos obras se elaboran en un mismo momento histórico sin solución de continuidad intelectual, es decir sin que medie contacto personal, académico o relación de investigación entre los dos autores encuadrados en ámbitos intelectuales claramente diferenciados.

17bis. Para hacerse una idea de la atmósfera moral de los Estados Unidos en la década de los setenta y del pesimismo impensante en su opinión pueden verse las primeras páginas del trabajo de Hannah Arendt "200 años de revolución americana" en Tiempos Presentes. Barna 2002, págs. 153 y ss. 
tinente europeo -y cuyas expresiones más acabadas eran el marxismo estructuralista de los Althusser y Poulantzas, en la neodialéctica de Horkheimer, Adorno y demás epígonos de la escuela de Frankfurt y las enseñanzas de Colleti, Cerroni y demás herederos de la tradición de Gransci empezaba a dar signos inequívocos de un agotamiento creativo y de un distanciamiento de los fenómenos de la vida, que demostraba que la realidad transcurría por derroteros que escapaban por completo a sus especulaciones. Era el resultado de una cada vez más extendida toma de conciencia de la inadecuación del marco conceptual racional para comprender y explicar unos hechos que habían desbordado los esquemas imperantes, y que no dudaban en renegar de una modernidad hasta entonces considerada sacrosanta. Ello no sólo significaba poner en tela de juicio las ideologías vigentes sino que implicaba además, una renuncia a la propia noción de ideología y, con ella, al conjunto categorial que durante casi quinientos años había impulsado y propiciado la transformación del mundo. Así pues, nada podía tener de extraño que en medio de la completa indiferencia hacia la reflexión de un obrar político deliberadamente entregado al saber técnico ${ }^{18}$, las construcciones sistematizadoras y omnicomprensivas de la historia y de la vida humana, se mostraran incapaces de soportar el contraste con la realidad de la que surgían en términos y formas que no tardarían en abrir camino a las tomas de posición de los Foucault, Derrida, Baudrillard y desde óptimas muy diferentes de los Furet, Lefort o Castoriadis. La hora de la postmodernidad había llegado.

Mucho se ha escrito acerca de lo que la postmodernidad ha supuesto o puede suponer todavía para el pensamiento contemporáneo, y no es éste el lugar para proceder al enjuiciamiento que aún está por hacer de un discurso que en gran medida permanece vigente. Al sólo propósito de enmarcar correctamente las obras de Rawls y Pocock, importa señalar que la postmodernidad es el estado de conciencia -casi cabría decir de espíritu- en que se encontraba sumida la inteligentzia europea cuando estos libros aparecieron y que en cuanto tal, representó y aún representa, una resultante de la crisis de una racionalidad que desde la denuncia de los excesos de las últimas manifesta-

18. En este sentido los trabajos que defienden "el fin de las ideologías" la tecnificación de la política, la tecnoburocracia y el gobierno de los managers y que durante mucho tiempo han venido siendo considerados un rebrote de lo que fuera el primer discurso antidemocrático de los Pareto, Mosca y Michels, deben ser entendidos como un intento más de imponer una cierta ideología, la ideología del poder, en el último momento histórico de las ideologías, en el tiempo de la desideologización, cuando los "ismos" se encuentran ya desacreditados entre otras cosas por el segundo proceso de "mundialización", un proceso que debe mucha de su razón de ser a la aplicación de la ciencia al hombre, a su vida y a su inmediata realidad vital. Paradigmáticos respecto de esta forma de pensar son los conocidos trabajos de Burkhan (Los Maquiavélistas Modernos, Buenos Aires, 1953) o Daniel Bell (El fin de las ideologías (1960), y, El advenimiento de la Sociedad postindustrial (1973), y en una medida que requiere de mayores matizaciones, Schumpeter, Capitalismo, Socialismo y Democracia, Buenos Aires, 1946. 
ciones de la modernidad no ha vacilado en renunciar a las explicaciones en favor de los acontecimientos, a los grandes sistemas de verdad y de definición apriorista, reduccionista y preformadora del discurrir histórico -el holismo y los llamados "ismos" ${ }^{19}$ - en favor de la descripción del simple discurrir de los hechos, a la verdad histórica en pro de un pensamiento débil que dé fe del veraz conocimiento de la vida, en otras palabras, a la necesidad de intepretar los hechos de la realidad cotidiana desde sus fenómenos, de emplazar al existir en el lugar del ser, de oponer lo fáctico a lo normativo, lo espontáneo, lo "natural", lo evidente y lo no creado, a cualquier idea de transformación preconstiutida desde la razón crítica.

Para el hombre postmoderno, o mejor -ya que la postmodernidad niega la éxistencia de un tipo humano encarnación de una abstracción racionalpara la condición posmoderna, lo fundamental está en la existencia cotidiana, en lo que vemos, en lo que experimentamos en el devenir diario de los acontecimientos. No hay regla, como tampoco hay orden, proceso o futuro ${ }^{20}$, hay lo que hay y que sólo adquiere virtualidad y existencià real en la medida y grado en que la prueba del contraste con la realidad en que se ha gestado -la "desconstrucción" a la que de manera reiterada alude Derrida- acredite su veracidad. La conclusión es obvia: el lenguaje entendido como comunicación y como expresión simbólica directamente emanada del fluir de las cosas, la cultura popular, el culto a lo minucioso, a lo anecdótico, a lo habitual, a lo pequeño, a lo insignificante ("small is beautifull»), al arte sin cánones: traducción de la espontánea fuerza creadora del instante; el derecho autogenerado, autosustentado y autorreferenciado en la realidad en la que arraiga y que no aspira a modificar o a imponer (el derecho autopoíetico de un Teubner ${ }^{21}$ ), el entendimiento de la acción del poder público -al margen de su significación como fenómeno político- como la capacidad de replicar a exigencias fugaces destinadas a procurar satisfacción satisfacción superficial e inmediata a una inmensa masa sociológica pasiva e inerme sin más valores que los que se aglutinan en torno a la imagen... son algunas de la señas de identidad de la postmodernidad,... si es que la postmodernidad puede tener alguna identidad.

$Y$ es que en el fondo, la postmodernidad es lo más opuesto que imaginarse cabe a la identidad entendida como sustancia, como naturaleza, como

19. El trabajo fundamental al respecto es el célebre ensayo de Popper, The Poverty of Historicism, 1957.

20. "Je pars de la décision à la fois théorique et methodologique qui consiste à dire: "supposons que les universaux n'existent pas", et je pose à ce moment-là la question à l'histoire et aux historiens: comment pouvez-vous écrire l'histoire si vous n'admettez pas a priori que quelque chose come l'Etat, la société, le souverain, les sujets existe?... C'est donc exactement l'inverse de l'historicisme que je voudrais mettre en place. Non pas donc interroger les universaux en utilisant comme méthode critique l'histoire, mais partir de la décision de l'inexistence des universaux pour demander quelle historie on peut faire" en "Naissance de la Biopolitique. $1 .^{\circ}$ cours". Paul Veyme, Foucault révolutionne l'bistoire, París, 1978.

21. Gunther Teubner, Law and autopoietic System. Oxford 1993. 
forma de ser irrenunciable a la que por principio se ve abocado el hombre. La postmodernidad resulta incompatible con la existencia de una materia original a la que los hechos de la vida van moldelando, dando forma, justamente, porque para la postmodernidad sólo tienen relevancia los hechos de la realidad considerados como eventos de la vida, como manifestaciones aisladas ajenas a cualquier cadena causal, y, ese es el contexto, en que tiene sentido aquel aserto de Foucault que advertía que en la postmodernidad "la identidad no existe, la identidad es una trayectoria, un itinerario" en el que -convendría añadir-, a la postre, termina disuelta sin que -y eso es lo verdaderamente relevante de la nueva condición- el hombre se vea afectado en nada por ello, sino, en cierto sentido, liberado. $Y$ es que la postmodernidad es una suerte de existencialismo despojado de angustia al que el hombre se ha acomodado y en el que termina por perder todo contenido problemático, por abandonar cualquier carga trascendente y capacidad crítica, pasando a cinvertirse en un ser evanescente, "mite ${ }^{22}$, entregado a una realidad que no domina, pero a la que tampoco estima necesario imponerse sino únicamente vivir y disfrutar de ella.

En este sentido Agnes Heller ${ }^{23}$, ha sostenido que la postmodernidad es una reacción, una respuesta negativa, una gigantesca denuncia contra las desviaciones de la modernidad que en cierto modo, se integra y forman parte de la propia modernidad. $Y$ es cierto que la postmodernidad se define ante todo por su contraposición con la modernidad, como una negación dialéctica de lo que la modernidad ha construido, de lo que la modernidad ha significado, hasta el extremo de que sin modernidad -y lógicamente sin sus excesos- la postmodernidad carecería de sentido, quedaría reducida a puro nihilismo disolvente. Pero la protesta postmoderna además de una inmensa purga de la modernidad equivalente poco más o menos, a la que emprendieran los reaccionarios románticos en relación con el racionalismo liberal del siglo XVIII y tras la cual el constitucionalismo se encontró finalmente el rumbo que le conduciría hacia la democracia representativa y hacia el Estado social de Derecho, representa también bastante más: algo muy negativo, un grave riesgo, algo que -si lo desprendemos de las particulares connotaciones que Luckas atribuyera a la expresiónbien pudiera merecer el calificativo de "segundo asalto a la razón": un desafío directo a la lógica que desde hace cinco siglos ha impulsado el avance del mundo. Y es que la postmodernidad lleva consigo un ataque frontal y directo a la razón histórica, entendida como la posibilidad del hombre de construir el mundo, de hacerse dueño de la vida, de su vida [...] y por tanto, equivale a poner en jaque la capacidad de la humanidad para prever, transformar, ordenar

22. El éxito del libro de Gustavo Zagrebelsky, Il Dirito Mite. Legge diritti giustizia, Turín 1992, sólo puede explicarse desde esa filiación postmoderna de dos sociedades que por razones diferentes se niegan a vivir su tiempo histórico o mejor dicho, el tiempo histórico que sus contemporáneos están viviendo ya.

23. Agnes Heller/Ferenc Fehér, Políticas de la Postmodernidad. Ensayos de crítica cultural, Madrid, 1989, pp. 148 y ss. 
y avanzar de manera anticipadora la marcha de los acontecimientos, a negar la propia concepción de historia que ha venido caracterizando a la conciencia occidental desde el Renacimiento, y al fin y al cabo, a deshumanizar la existencia humana. La postmodernidad más allá de sus efectos coyunturales y de sus cuestionamientos puntuales, comporta un cuestionamiento a priori al modo de razonar, una negación del juicio crítico que alimenta a la modernidad.

Así las cosas, el gran reto de superar la protesta postmoderna puede ser afrontado desde dos perspectivas diferentes: una primera que tratando de superar los excesos de la modernidad acepta mantener como válidos los supuestos propios de su razón misma, y otra segunda que admitiendo que la postmodernidad comporta una serie y definitiva crisis de toda una forma de concebir una razón que en adelante ya no podrá ser la misma -lo que equivale a repudiar por inadecuadas tanto las teorías críticas, como la totalidad de las doctrinas holistas desde el historicismo hasta el idealismo-, reconoce que la postmodernidad no es una simple puesta en cuestión de los elementos más disparatados de la racionalidad de la que en un instante posterior pueda surgir incólume una modernidad más madura, sino un ataque frontal y directo a sus postulados de principio que se opera en un instante en el que todas las certidumbres sobre las que descansaba la conciencia moderna -incluidas las categorías de tiempo y espacio- parecen anunciar una inminente quiebra. Ello supone admitir que la manera de entender la razón crítica hasta ahora imperante $-\mathrm{y}$ no la razón histórica misma- ha sido definitivamente superada y en consecuencia, proclamar la conveniencia de reconstruir la conciencia histórica -que no es otra cosa que el conocimiento consciente que el hombre tiene de sí y de sus posibilidades de forjar su propio mundo- desde un terminante rechazo a todo lo que signifique predeterminar el proceso histórico, imponer los resultados del tiempo por venir, lo que, en resumidas cuentas, se traduce en emplazar la deconstrucción allí donde hasta ahora habían estado situadas las teorías críticas. Dentro de la primera opción se localiza el razonamiento de John Rawls, en el segundo se sitúan los planteamientos de John Pocock.

\section{John Rawls versus John PoCOCK: Derecho frente a Justicia, "EL Buen GOBIERNO"}

Tanto la Teoría de la Justicia de John Rawls como el Momento maquiavélico de John Pocock se insertan en un contexto vinculado a una crisis de la postmodernidad que es también, la crisis de la formalización y desustanciación de la Política que por aquella época comenzaba a hacerse notar en las sociedades democráticas, aunque lo hacen desde órdenes conceptuales diferentes: Rawls buscando recuperar la razón crítica a través de un formalismo que llama "Justicia" y que en resumen consiste en las reglas del Derecho. Pocock reconociendo la necesidad de deconstruir la realidad desde un lenguaje contextualizado en el tiempo y que le termina llevando a la Política. Y 
es en esta misma reacción crítica a las viejas ideologías donde se debe encuadrar la polémica que hoy enfrenta al contractualismo con el comunitarismo profesado por autores como Sandel ${ }^{24}$, Walzer ${ }^{25}$, Taylor ${ }^{26}$ y muy especialmente MacIntyre en su importante ensayo After Virtue ${ }^{27}$, quienes desde posiciones no coincidentes con la de Pocock en su contenido y en los parámetros que guían su modelo de conocimiento ${ }^{28}$, tienen en común con él oponer un radical rechazo a los postulados de Rawls y de aquellos pensadores que sitúan sus planteamientos en el terreno de la reconstrucción de la legitimidad democrático-representativa.

El neocontractualismo propugnado por John Rawls, y en el que con importantes matices coincidirán autores como Brian Barry y Robert Nozick $^{29}$, se propone afrontar la crisis del Estado Constitucional reformulando sobre nuevos presupuestos el viejo pacto social de las teorías de Suárez, Grocio, Puffendorf, Althusio o Locke. Se trata de una propuesta que atiende a reconstruir la fórmula de legitimidad que está en el origen de la convivencia política del Estado liberal y especialmente del individualismo garantista, identificando "Justicia" con igualdad de derechos: atribuyendo à la igualdad en el disfrute de la libertad negativa la condición de fin primordial y objetivo último de una sociedad democrática ${ }^{29 \mathrm{bis}}$. Independientemente de las críticas que desde la lógica del pacto pudieran oponerse a semejante propuesta y más allá del hecho de que tras esta tesis pueda sub-

24. MiCheL SANDEL, Liberalism and the Limits of Justice, Oxford 1982 escrito en polémica con Rawls, y Democracy's Discontent: America in Search of a Public Philosophy. Belknap Press. 1996.

25. WALzER, Spheres of Justice, Oxford, 1983.

26. Charles TAYlor, Philosophical Papers, Cambridge, 1985 y The Ethics of Authenticity. Cambridge, 1991.

27. Alasdatr MacinTYre, After Virtue, Notre Dame. Ind. 1984.

28. Nada tiene que ver Pocock ni con el comunitarismo ni con las corrientes que dentro de él se consideran a sí mismas republicanas: el "republicanismo" propugnado por Pettit y otros autores. Pocock se diferencia de ellos en que su renuncia a la razón crítica lo es también a los "ismos", y en su interés por estudiar el pensamiento desde el discurso. Aristóteles y la república no son para Pocock una ideología, sino las claves de un discurso que puede o no ser escrito en el presente.

29. El neocontractualismo no es una escuela de pensamiento homogéneo, sino que bajo un denominador común contiene numerosas matices que llevan a conclusiones políticas muy distintas. En una línea similar a Rawls aunque con importantes diferencias se sitúan Brian Barry, Teoría de la Justicia. Barcelona 1995 y La Teoría Liberal de la Justicia. México, 1993 y Robert Nozick, Anarquía, Estado y Utopia. Mexíco, 1988.

29bis. Las teorías de la Justicia de Rawls y "la vuelta al derecho" que ellas propugnan, no son simples enmiendas teóricas sino el paradigma sobre el que descansa toda una àcción política que durante los años 90 ha impulsado la política norteamericana en América Latina -una política que tiene su máxima expresión en la preocupación por fortalecer las instituciones judiciales manifestada y puesta en práctica por el PNUD- en un intento por aumentar la democracia donde otrora estuvieron las dictaduras de los espadones militares. No deja de resultar significativo que las críticas a Rawls -hoy ya generalizadas- sean paralelas y simultáneas al desenvolvimiento de las constituciones "semánticas" - para utilizar la terminología de Loewemstein- a la que hoy asiste América Latina. 
yacer la filosofía del mercado y la lógica de un hombre económico que carece de existencia histórica, la principal objeción que desde la perspectiva de la legitimidad democrática cabe argüir en contra de esta tesis es que el problema actual de la democracia no reside tanto en la redefinición de sus postulados paradigmáticos desde un formalismo y un juridicismo al que el "velo de la ignorancia" impide cuestionar, cuanto en su irrealismo, su tendencia a la abstracción especulativa y su falta de concreción en la vida práctica. Dicho de otro modo el modelo de Rawls esta aquejado de dos males: primero, la crisis de la legitimidad democrática es una crisis de efectividad, de distancia entre deber ser democrático y ser político, entre teoría y praxis y no un conflicto que contrapone alternativas ideológicas rivales reconducibles por el consenso y armonizables a través del derecho; y segundo, lo que el mundo postmoderno reprocha a la razón democrática no es un solo un determinismo que ahoga al hombre en el curso de un futuro preconcebido, de antemano, sino también la insensibilidad a los diferentes matices de una realidad que es distinta en cada momento y espacio geográfico y que como tal, exige ser tenida en cuenta desde sí misma y no desde presupuestos omnicomprensivos que todo lo entiendan y explique. No cabe hablar de un tipo universal de Estado Constitucional simplemente porque dicho concepto no tiene lugar y carecer de virtualidad para afrontar el conocimiento de la realidad.

En este punto Sandel o Taylor y Pocock, coinciden en reprochar a Rawls un retorno a Kant obstinado en reconstruir las reglas formales desde las que es posible articular el vivir en una comunidad política, y le oponen un Aristóteles preocupado por determinar cuál es y cómo se obtiene el bien común. Pero mientras los primeros se mantienen en la ortodoxia del aparato categorial de la razón crítica, John Pocock edifica su respuesta desde una deconstrucción que en cuanto toma como referencia la vida real, sitúa el discurso donde otros colocan la ideología. Desde semejante tipo de consideraciones parece obvio que autores como Rawls, Habermas o Habërle -por citar tres penadores especialmente recurrentes para el derecho constitucional de nuestros días- poco o nada tienen que decir a una reflexión a la que repugnan por igual los "ismos" y las abstracciones y generalizaciones universalizantes de la politica $^{30}$. En esto se distingue justamente la propuesta de Pocock, tanto en lo que se refiere a sus modos de conocimiento, como a la alternativa que ofrece a lo que, en palabras de Sandel, se conoce como Procedural Republic, la

30. En honor a la verdad hay que decir que el actual Rawls - un segundo Rawls que se manifiesta en trabajos como La Justicia como equidad. Una reformulación, Barcelona, pp. 173 y ss.- no es ya el mismo de 1971, porque ha efectuado una profunda revisión de su planteamiento neokantiano para tratar de dar cabida en sus tesis a la República y a los valores de la virtud cívica, en los que ve la única garantía posible de conferir cierta "estabilidad" (sic.) a la democracia. El problema es que pese a sus esfuerzos, su intento de meter en el mismo saco formalismo jurídico y democracia sustancial, hacen que su postrera obra se convierta en pura ideología, algo que justamente pretendió conjurar hace treinta años, cuando escribió su Teoría de la Justicia. 
República Procesal ${ }^{31}$. Y es que Pocock se sirve de la crisis de la democracia representativa para replantearse la licitud y la adecuación del modo que ella ha tenido de acercarse y de tratar de conocer la realidad, y lo más llamativo de todo es que lo hace sin decirlo ${ }^{32}$, y sin parecer que lo hace.

\section{EL «MOMENTO MAQUIAVÉLICO» DE JOHN POCOCK: LA CONTEXTUALIZACIÓN DEL DISCURSO POLÍTICO EN EL TIEMPO. EL PARADIGMA REPUBLICANO CÍVICO}

La propuesta de John Pocock supone pues, al mismo tiempo, un intento de reconstrucción de la razón moderna desde las categorías de la "deconstrucción», y el redescubrimiento -la relectura- de un discurso histórico hasta

31. MiChAEL SANDEL, Liberalism and the Limits of Justice Oxford 1982, p. 269, sostiene frente a propuesta de Rawls la necesidad de sustituir la actual "Procedural Republic" (República Procesal) por una nueva "National Republic" (República Nacional) dotada de contenidos democráticos materiales fundados en valores específicos. Sandel ha insistido en sus tesis en trabajos posteriores "The Procedural Republic and the Unencumbered Self" en Political Theory, 12/1, pp. 81-96 y "The Political Theory of the Procedural Republic" en Revue de Metaphysique et de Moral, 1993 , n. ${ }^{\circ}$, pp. 57/68.

32. Una excepción a esta deliberada ausencia de reflexión metodológica (que además de una respuesta a las exageraciones y desviaciones de las teorías que se mueven en la órbita de la razón crítica, se ha convertido en un elemento distintivo del grupo de Cambridge) en su Virtue, Comerce, and History, Cambridge 1985, pp. 1-34 que significativamente lleva por título "The state of the art": "No obstante los cambios que afectan a esta rama de la historiografía en las dos últimas décadas, se han caracterizado por un desplazamiento del énfasis desde la historia del pensamiento (y más todavía desde la historia "de las ideas") hacía algo ciertamente diferente que bien pudiera denominarse "historia de la palabra" ("history of speech") o "historia del discurso" ("history of discurse"), aún cuando no se trate de una problemática irreprochable, ni sea esta la mejor terminología para definirla. Una visión retrospectiva sitúa los orígenes de este movimiento en los análisis y descubrimientos lingüísticos propiciados por los filósofos del Cambridge de los años $1950 \ldots$ otro en las teorías del "speech-act" desarrolladas en Oxford por los mismos años [...] Ambas situaban su foco de atención sobre la gran variedad de cosas que podían ser dichas, potencial o efectivamente, sobre la diversidad de contextos lingüísticos que determinan cuanto puede ser dicho (los actos de enunciación), y que al mismo tiempo actúan (modificando) sobre cuanto puede ser dicho [...] La historiografía entonces emergente, hizo énfasis en dos centros de interés: primero la variedad de léxicos (idiomas) o "lenguajes" como sería mejor llamarlos, en que podía ser expresada la argumentación política [...] en segundo lugar, su participación en el debate político en cuanto actores históricos que se responden unos a otros en una diversidad de contextos lingüísticos, históricos y políticos, que confiere a la reconstrucción histórica de su argumentación un entramado extraordinariamente rico [...] La pregunta de por qué estos acontecimientos constituyen una auténtica revolución en la historiografía del pensamiento político requiere que se describa el "estado del arte" antes que ese hecho tuviera lugar [...] La primera y más inmediata cuestión al respecto, es que siempre ha existido una necesidad (a la que era preciso dar respuesta) de reescribir la historiografía del pensamiento político y sus implicaciones, y de definir su práctica en términos más rigurosamente históricos. Es usual sugerir que in illo tempore las disciplinas teoría política e historia del pensamiento político habían llegado a confundirse y que el advenimiento de una filosofía analítica lingüística profundamente antihistórica contribuyó a propiciar su distinción. Pero si-los filósofos lingüísticos no se sintieron obligados de escribir la historia, los historiadores tardaron en vencer su renuncia a ocuparse o a contribuir a la filosofía de los "speech acts" o de las proposiciones." 
hace poco olvidado: el pensamiento de los Maquiavelo, Harrington, Rousseau y Jefferson. Y Pocock se propone afrontar esa tarea desde dos supuestos previos: el lenguaje y la contextualización del tiempo histórico, o lo que es lo mismo, lo que él denomina "Momento maquiavélico", la toma de conciencia del significado del tiempo como categoría instrumental de la razón humana.

Con relación a la primera cuestión, John Pocock articula su trabajo en torno a lo que en la jerga postmoderna se llamaría un "linguistic turn "33, un giro hacia la palabra que soporta una nueva manera de abordar el estudio del pensamiento en la que el lenguaje pasa a ocupar el lugar que la teoría política clásica había reservado a la "idea" tout court, o la posición que las ciencias positivistas y desminificadoras concedían a los supuestos precomprensivos y a los condicionantes externos al razonamiento. El lenguaje, es decir el código expresivo que recoge, nutre y da vida a la argumentación de un autor, tiene sentido en sí mismo, es expresión en forma de discurso de una determinada manera de pensar y de abordar los problemas, que se hace evidente a partir de la lectura de los textos, del estudio del proceso de gestión, adopción y conformación de sus conceptos, y en el conocimiento de su operatividad interactiva en el marco inmediato en que interviene: el debate y la acción práctica. En ese sentido, lo que Pocock propugna, es la necesidad de situarse ante la palabra concebida como "speech act": como acción que se enuncia -que se verbaliza- en un lenguaje que, a su vez, existe en un contexto particular pefectamente singularizado. Ello implica, de una parte, la exigencia de una rigurosa contextualización como requisito previo a la correcta interpretación de cualquier sistema de pensamiento, evitando que con el pensamiento se operen fenómenos como los "falsos amigos" de la lingüística, esto es, incardinar un argumento en un marco diferente a aquel en el que originariamente fue pensado que le haga variar radicalmente de sentido o, incluso, pervierta completamente su significación sin, en apariencia, alterar en nada su estructura formal; y de otra, supone entender el lenguaje emplazando en el mundo de lo real y operativo, como un hecho más de lo que los hombres piensan en

33. "El cambio de siglo fue testigo de una crisis filosófica en el fundamento de las matemáticas [...] una crisis comparable a la que actualmente viven el concepto y la comprensión del lenguaje [...] La gramatología, la semántica, el estudio de la interpretación del significado y de la actual práctica interpretativa (la hermenéutica), los modelos de los posibles orígenes del habla humana, el análisis formal y pragmático y la descripción de los actos y la representación lingüísticos [...] No obstante, si tenemos en cuenta que el actual "giro hacia el lenguaje" no sólo afecta a la lingüística, a las investigaciones lógicas de la gramática, a las teorías de la semántica o de la semiótica, sino también y en gran medida a la filosofía, a la poética y a los estudios literarios, a la sicología y a la teoría política [...] (y) [...] supone una ruptura radical con la sensibilidad y premisas tradicionales [...] Nuestros actuales debates sobre las gramáticas genero-transformacionales, sobre los actos del habla, sobre los modelos estructuralistas y deconstruccionistas d e la lectura textual, en una palabra, nuestro enfoque actual sobre "el significado del significado" derivan de la poética y la práctica experimental de Mallarmé y Rimbaud. El período comprendido entre la década de 1870 y la mitad de la década de 1890 define el programa de nuestro actual debate, que sitúa el problema de la naturaleza del lenguaje en el mismo centro de las sciences de l'homme filosóficas y aplicadas." George Steiner, Presenciales reales, Madrid, 1996, pp. 46-6. 
el ámbito de lo cotidiano, en lo que Foucault y los postmodernos llaman lo "micro". Frente a las ideologías que todo lo entienden y todo lo pueden explicar, surge ahora la necesidad de reconstruir el significado del pensamiento desde la propia, particular y minúscula realidad de la que es parte.

Pero para que ello sea posible, Pocock debe situar el punto de arranque de todo su proyecto de reconstrucción del razonamiento histórico en torno a la categoría de tiempo. "Los hombres dicen que el tiempo dice que no, que permanece, que son los hombres los que pasan" afirma el viejo proverbio. Y es que el tiempo como realidad objetiva, como categoría absoluta, inalterable e imperecedera, simplemente no existe y no ha existido nunca ${ }^{34}$. El tiempo, al igual que cualquier otra abstracción humana, tiene un sentido relativo vinculado a la específica realidad que lo produce. Por eso no existe un sólo tiempo, no cabe hablar de un tiempo unívoco, los hombres no han conocido una única idea de tiempo, ni han venido participando ininterrumpidamente del mismo concepto de tiempo, por la sencilla razón de que también el tiempo tiene sus tiempos. Desde la noción cíclica propia del tiempo antiguo (presente en un Platón o un en Aristóteles y de la que son tributarios y partícipes el Panta rei heraclitiano, las siete años buenos seguido de los siete malos de las míticas plagas de Egipto o la idea de reencarnación hinduista), hasta el concepto cristiano de tiempo marcado por el hecho escatológico de la salvación, y que se define por reconocer un cierto ámbito de libertad al hombre limitado por la verdad revelada y por la fe, la existencia humana ha conocido un amplísimo elenco de formas de tiempo, una de las cuales es la que nos resulta propia: el tiempo de la modernidad, el tiempo racional, un tiempo (fortuna en expresión de Maquiavelo) llamado historia, y que tiene como presupuesto el hecho de que un hombre provisto de razón y consciente de su propia racionalidad -en posesión de un juicio crítico-, sea capaz de crear su mundo, de construir su propia realidad a través de un proceso, aplicando a las cosas su saber en el deliberado propósito de transformarlas.

No es fácil percibir con claridad lo que de novedoso pudo representar la introducción de semejante concepción del tiempo en el Renacimiento, cuando se está inmerso en un mundo que ha absolutizado hasta el paroxismo su propio momento, es decir, su particular forma de tiempo, y no admite otra racionalidad que la que conoce y en la que vive. Pero basta echar una ojeada a los jirones de otros mundos que todavía nos rodean para entender lo que ello debió significar hace quinientos años, cuando la concepción racional del tiempo hubo de coexistir con otros patrones de comportamiento. Los retazos de culturas orientales, islámicás o africanas que todavía resisten a la mundialización euro-

34. Toulmin y Goodfield, El descubrimiento del Tiempo, Barcelona, 1990. G. Whitrow, $E l$ Tiempo en la Historia, Barcelona, 1990. Alfred CRosby, La Medida de la realidad, Barcelona, 1997. Jo Ellen BANeTt, El péndulo del Tiempo, Barcelona, 2000. La concepción pocopiana del tiempo es altamente deudora de las ideas expresadas por el que fuera su maestro en Cambridge HERBERT BUTTERFIELD, The Origins of Modern Science, Londres 1958. 
pea, expresan lo que es vivir en un mundo ajeno a nuestro sentido del tiempo, en el que el reloj no es imperativo de la existencia cotidiana, y en que la concepción temporal de la vida no ocupa lugar: los hombres no hacen el mundo se limitan a vivir en una realidad que es hecha por algo o alguien ajeno a ellos, las fuerzas de la naturaleza, la voluntad divina, el fatum, o la simple nada como pretenden Nietzsche o los postmodernos ${ }^{35}$. Frente a esa construcción del mundo externa al hombre para la que el hombre es un dato de una realidad que en cierta medida le transciende y le resulta autónoma, los humanistas cívicos de la Italia renacentista proclamaron la existencia de un mundo para el que el concepto de tiempo irrumpía como expresión de la capacidad de la conciencia humana para entender y construir la vida; de un mundo que representaba una forma de comprender las cosas para la que por primera vez la realidad pasaba a ser historia y la historia a ser percibida como un proceso en el que los hombres dominaban, se enseñoreaban de los hechos y, en consecuencia, de un mundo que les permitía crear su propia realidad, su propia vida. El tiempo laico (secular) del que habla Pocock, es un tiempo particular en el que se opera el reconocimiento consciente de la capacidad del hombre para construir un

35. Al respecto conviene traer a colación aquí una referencia recogida por Kapuscinski en su conocido y por tantas razones magnífico libro Ébano: «El europeo y el africano tienen un sentido del tiempo completamente diferente; lo perciben de maneras dispares y sus actitudes también son distintas. Los europeos están convencidos de que el tiempo funciona independientemente del hombre, de que su existencia es objetiva, en cierto modo exterior, que se halla fuera de nosotros y que sus parámetros son medibles y lineales. Según Newton, el tiempo es absoluto: "Absoluto, real y matemático, el tiempo transcurre por sí mismo y, gracias a su naturaleza, transcurre uniforme; y no en función de alguna cosa exterior." El europeo se siente como su siervo, depende de él, es su súbdito. Para existir y funcionar, tiene que observar sus férreas e inexorables leyes, sus encorsetados principios y reglas. Tiene que respetar plazos, fechas, días y horas. Se mueve dentro de los engranajes del tiempo; no puede existir fuera de ellos. Y ellos le imponen su rigor, normas y exigencias. Entre el hombre y el tiempo se produce un conflicto insalvable, conflicto que acaba con la derrota del hombre: el tiempo lo aniquila [...] los africanos perciben el tiempo de manera bien diferente. Para ellos el tiempo es una categoría mucho más holgada, abierta elástica y subjetiva. Es el hombre el que influye sobre la horma del tiempo, sobre su ritmo y su transcurso (por supuesto, sólo aquel que obra con el visto bueno de los antepasados y de los dioses). El tiempo, incluso, es algo que el hombre puede crear, pues, por ejemplo, la existencia del tiempo se manifiesta a través de los acontecimientos, y el hecho de que un acontecimiento se produzca o no, no depende, sino del hombre. Si dos ejércitos no libran batalla ésta no habrá tenido lugar (es decir, el tiempo habrá dejado de manifestar su presencia, no habrá existido). El tiempo aparece como consecuencia de nuestros actos y desaparece si lo ignoramos o dejamos de importunarlo. Es una materia que bajo nuestra influencia siempre puede resucitar, pero que se sumirá en estados en hibernación, e incluso en la nada, si no prestamos nuestra energía. El tiempo es una realidad pasiva y, sobre todo, dependiente del hombre. Todo lo contrario de la manera de pensar europea", pp. 23-24. En el excelente relato de Kapuscinski se contiene una descripción perfectamente postmoderna de la realidad actual africana que es el punto de contraposición exacto de libros como Les damnés de la terre, de Frantz Fanon o Las Venas Abiertas de América Latina de Eduardo Galeano, que en los años sesenta y setenta fueron el símbolo de toda una generación, y sirve para evidenciar el contraste que media entre el voluntarismo de la literatura revolucionaria y liberadora del último momento de la era de las ideologías y el actual pesimismo postmoderno, un pesimismo que es a la vez resignación ante la fuerza de los hechos, ante la realidad impensante. 
mundo que en cuanto obra humana se define como histórico: la historia es una forma de referirse a la vida cuando la vida se concibe como el resultado de la acción humana, de un hombre que emancipado del tiempo natural pasa a percibir la vida como historia: como un proceso autoconstruido. Pero el tiempo no es un absoluto situado al margen -valga la redundancia- del tiempo y del espacio, es sólo un "Moment" creado por la razón humana para comprender el mundo o, y mejor dicho, para entender un cierto mundo particular.

Pero si el tiempo no es un parámetro eterno, un factor fijo inmutable ¿cómo interpretar el mundo cuando ha cambiado el concepto mismo de tiempo? Se trata de una cuestión a la que Pocock no pretende dar respuesta desde el instante en que su denuncia no es una renuncia a la modernidad sino a una determinada expresión de la modernidad: aquella que ve la razón como un proceso crítico proyectable sobre un futuro cierto. Su tiempo es fijo a la veź que es relativo, esto es en la medida en no pierde conciencia de su condición de supuesto abstracto, de producto de una razón humana que como tal está condenada a ser perecedera. El tiempo se hace así en Pocock "maquiavélico", es decir, instrumento de comprensión de una vida humana que en este momento de crisis de la democracia representativa sólo puede edificar su identidad desde y sobre el paradigma de la Política.

\section{EL PARADIGMA REPUBLICANO CÍVICO}

A partir de los años setenta y coincidiendo con la crisis mencionada, los Estados Unidos vienen asistiendo a una auténtica eclosión de la República que se manifiesta tanto en el terreno del pensamiento en los trabajos de Sandel y de los comunitaristas anteriormente aludidos, en el de la historia en los libros de Bailyn y Wood, como en los propios intentos de cambio y de reforma legal que llegan a afectar incluso a la propia Constitución ${ }^{36}$, pero en medio de tal

36. La última enmienda a la constitución americana sólo se explica desde y en el impulso generado por este revival republicano. La XXVII enmienda dice: "Ninguna ley que modifique el montante de la compensación por servicioś debida a los Senadores y Representantes podrá entrar en vigor (shall take effect) antes de que se produzca una nueva elección de Representantes". En principio, y a juzgar por su contenido la enmienda no parece tener gran trascendencia; ahora bien la cosa cambia cuando se tiene en cuenta su proceso de tramitación y el contexto en que ello tuvo lugar. Su autor no es otro que James Madison, que la redactó junto con otras en el propósito de incorporar una declaración de derechos a la constitución. Las diez primeras fueron ratificadas y en 1791 pasaron a formar parte de la constitución en forma de sus diez primeras enmiendas, otras -entre las que se encuentra la actual XXVII enmienda- fueron abandonadas a medio camino al no contar con la ratificación de las legislaturas de los tres cuartos de los Estados estipulada para la reforma constitucional y fue olvidada. Redescubierta casi ciento setenta años después por un estudiante de derecho, en los años setenta y ochenta recogió el quórum necesario en medio del entusiasmo de las diferentes legislaturas de los Estados, beneficiándose del hecho de no verse afectada por la norma que establece un plazo temporal limitado para proceder a la ratificación de las enmiendas antes de que decaiga. Para valorar adecuadamente lo que su incorporación a la constitución norteamericana puede significar en orden a la actual estado de actitud 
eclosión se opera al tiempo una gran confusión: la vuelta a la República no siempre consiste y resulta ser también, una vuelta a la Política en el sentido aristotélico del término. Es este el instane en que adquieren su importancia los esfuerzos de Pocock, Skinner y Dunn por recuperar en lo sustancial los viejos trazos del pensamiento de los Maquiavelo, Guicciardini, Guiannotti, Harrington, Rousseau, Jefferson, para construir un discurso centrado en la aspiración del "buen Gobierno": una politica basada en la vita activa incardinada en un vivere civile que reparta entre los hombres la Justicia. Y ¿en qué se concreta ese buen Gobierno? Fundamentalmente en un paradigma construido en torno a tres postulados:

1. $\quad$ Para empezar en un entendimiento clásico de la Política. Frente a la concepción de la política como poder, el discurso republicano renuncia a definir la Politica en los términos habituales de la lógica de la dominación y del séquito descritos por Weber, y la explica como un principio sustancial basado en el autogobierno: como un vivere civile al que la vita activa eleva a la condición de supuesto efectivo. El hombre es un animal político, y la ciudadanía la actividad más digna a que puede aspirar el ser humano, en consecuencia, sólo mediante la apropiación de la Ciudad por unos hombres plenos de virtud cívica, puede obtener la política su dimensión moral y otorgar a la acción pública su propia significación: justificar la existencia humana. La Politica es irrenunciable para un hombre que se reclama ciudadano: sin uso en la práctica, sin ejercicio directo de la ciudadanía, no hay vida digna. Y cuando una comunidad carece de ciudadanos es porque la condición humana ha sido antes enajenada, porque la Ciudad está corrompida y urge salvarla. De aquí que Alain pueda afirmar que "el poder es siempre monárquico", y de aquí también, que sea en el espíritu y no en las leyes, en el respeto cotidiano a los postulados de principio y no en los órganos del Estado, dónde reside la última y mejor esperanza de la democracia; y de aquí también, la importancia de la educación para la configuración de la ciudadanía, para educar a la ciudadanía en la virtud cívica.

2. ${ }^{\circ}$ Pero ¿cómo es la Ciudad que debe construirse y en qué consiste la Justicia que en ella puede articularse? La pregunta ofrece dos respuestas: a) de una parte, el vivere civile no elimina los valores particulares de cada grupo o colectivo donde los hombres se integran, sino que les impone límites que son los que derivan del hecho de vivir juntos: la solidaridad, el bien común, la justicia social, en suma, los que potencian el ser común en detri-

y preocupaciones de la opinión pública norteamericana, basta recordar que la ERA (la enmienda que pretende recoger en el ámbito federal el derecho a la igualdad de las mujeres) todavía no ha conseguido ser aprobada por tres cuartas partes de las legislaturas de los Estados y ha decaído. Otro tanto de lo mismo sucede con cuestiones como la prohibición de repetir mandatos en el Senado, o con las donaciones de dinero en las campañas electorales (el famoso soft money) que se ven afectadas por apasionantes debates en la doctrina, los tribunales (incluida la Corte Suprema) y la opinión, y que están dando lugar a importantes modificaciones legislativas que sólo pueden ser correctamente entendidas desde una comprensión previa de esa vuelta a la República que actualmente viven el derecho constitucional y la sociedad norteamericana. 
mento de las tendencias desintegradoras y centrífugas que amenazan la Ciudad, los que hacen posibles un patriotismo republicano que resulta imprescindible para alcanzar la gobernabilidad, para fijar la república en el tiem$\mathrm{po}^{37}$. b) De otra ello implica la necesidad de establecer equilibrios (balance) dentro de la Ciudad entre los diferentes valores en pugna lo que supone reconocer que el buen gobierno de la sociedad pasa por la articulación equilibrada de la pluralidad de intereses en pugna que en ella existen. Todos son aceptables con tal que no se impongan completamente a los demás ${ }^{37 b i s . ~ E l ~}$ único valor absoluto es la ciudadanía que sin llegar a ser un valor formal y hueco, es un receptáculo donde cabe la pluralidad. Dentro de la ciudadanía cualquier valor resulta admisible siempre y cuando se pueda encontrar compensado con otro.

3..$^{\circ}$ La libertad de los antiguos precede a una libertad de los modernos que la presupone. No es que los derechos subjetivos perezcan sacrificados a la libertad política, sino que sin libertad ciudadana no cabe habler de libertad del hombre. Si el hombre no es dueño de su comunidad, si el ciudadano no es capaz de autogobernarse, de impedir que una fuerza externa gobierne su voluntad ¿cómo puede aspirar a disfrutar de un ámbito de libertad negativa? La distinción libertad negativa/positiva del contractualismo cae víctima de un requisito previo del que sus clásicos habían prescindido, y la escisión y la subordinación del estado a la sociedad característica de la modernidad se ven sustituidas por una invocación a la acción positiva en la Ciudad. La virtud cívica pasa a precisar y a requerir de la virtú ciudadana, de una ciudadanía capaz de obrar políticamente y al servicio del supremo

37. "Estabilizar la república en el tiempo" es una preocupación de Maquiavelo -cabría decir que la gran aspiración de Maquiavelo que se encuentra presente en la palabra "stati" utilizada por el autor en el Príncipe, que hace referencia a lo que hoy conocemos de manera habitual por gobernabilidad. Gobernabilidad es una expresión equívoca derivada de una discutible traducción del inglés "government", que alude al hecho de conferir permanencia en el tiempo, de dar estabilidad a la República -entendida como comunidad de convivencia política o estado- frente a los acontecimientos que amenazan con destruirla; en suma; a la lucha de la virtud cívica hecha virtù maquiavélica, con la Fortuna. Nada tiene que ver la palabra gobernabilidad con el gobierno entendido como poder ejecutivo, como uno de los brazos de un Estado que se encuentra por encima de él y que lo integra en su seno. La expresión inglesa "government" es predicable tanto del gobierno como del Estado, y según los contextos puede ser traducida por uno y otro significado; hay que estar en cada caso al contexto en que se inserta ya que de otra forma se corre en el riesgo de incurrir en el fenómeno que los lingüistas llaman "falsos amigos": atribuir a una expresión procedente de otra lengua y formalmente idéntica a la del propio un significado radicalmente opuesto que repugna al sentido que tiene en el lenguaje originario. Es lo que sucede, por ejemplo, con la expresión Ong (organizaciones no gubernamentales), que en castellano debieran ser denominadas organizaciones no estatales para poder aludir de esa forma a su condición de organizaciones pertenecientes o provenientes de una sociedad contrapuesta al estado y resaltar así su desvinculación con el poder ejecutivo.

37 bis. El equilibrio (balance) interno de la república no debe confundirse en ningún caso con el pluralismo al que se refieren KuYLINCA y otros autores, el primero deriva de lo que la concepción de la política clásica llamó "mito de Venecia" y hace referencia a la necesidad de estructurar la sociedad política como un punto de encuentro de intgereses que tienen derecho a subsistir en tanto en cuanto unas no aspiren a imponerse y suprimir a las otras y admitan su subordinación a la ciudad. La segunda alude a una integración cultural que se mueve dentro de los límites de lo que Habermas denomina "la inclusión del otro". 
arcana de la democracia ${ }^{38}$, porque sin virtú no hay democracia. Y es que como recuerda Alain, "quelle que soit la Constitution, dès que les citoyens se laissent gouverner, tout est dit, ${ }^{39}$.

Estos son, expuestos de manera breve y casi telegráfica, los supuestos referenciales que resumen el paradigma republicano. Y desde esta perspetiva parece obvio conceder que el trabajo de los autores de Cambridge está sirviendo para recuperar los parámetros estructurales de una determinada forma de democracia, y que ha conseguido demostrar que no existe sólo una legitimidad democrática, es decir que como recuerda con insistencia Bernard Manin, el sistema representativo no ostenta el monopolio de la democracia. Por eso, cabe decir sin temor a incurrir en exageraciones que el Machiavellian moment de John Pocock tiene una talla equiparable a la Teoría de la Justicia de John Rawls, sólo que desde el lado contrario, desde una trinchera distinta de la democracia. Y en este sentido representa un impresionante intento de contribuir a refundar el pensamiento democrático desde una apelación a los valores de los antiguos y a un humanismo cívico que es coherente en todo con el tiempo histórico que le ha tocado vivir en suerte: un Moment de crisis en el tiempo conceptual de la modernidad, de cuestionamiento de la razón y la historia, que todo indica no será definitivo.

38. No debe confundirse la "virtud cívica", la virtud ciudadana consistente en amar a la Ciudad y en hacer de ese amor el primer principio de la ciudadanía, con la "virù" maquiavélica que ve en la acción y è la lucha contra la vida -Fortuna- un presupuesto de la propia existencia que a la vez lleva al hombre a destruir esa misma realidad en que se halla inmerso. la virtù exige una cualidad y requiere un atributo: la cualidad es la excelencia cívica que impone al hombre orientar su actuar más allá de sus propios intereses hacia la consecución del bien de la Ciudad; el atributo consiste en el coraje civil, en el arrojo para batirse por el interés común sin reparar en las consecuencias que para la propia persona puedan derivar de sus acciones; sin ellas no hay virtù y $\sin v i r t u ̀$ no puede haber democracia. 